\title{
Elderly Care Ethics: A Glance on Principlism
}

\section{Abu Sadat Mohammad Nurunnabi', Shaorin Tanira², Sadia Akther Sony ${ }^{3}$}

1. Dr. Abu Sadat Mohammad Nurunnabi, Assistant Professor, Department of Anatomy, OSD, Directorate General of Health Services (DGHS), Dhaka. Email: shekhor19@yahoo.com (Corresponding author)

2. Dr. Shaorin Tanira, Assistant Director (Health), MCH-FP Clinic, Manabik Shahajya Sangstha (MSS), Dhaka.

3. Dr. Sadia Akther Sony, MPH student, Department of Public Health and Informatics (DPHI), Bangabandhu Sheikh Mujib Medical University (BSMMU), Dhaka.

\begin{abstract}
Being a low-income country of South Asia region, Bangladesh has been struggling with its health budget for increasing elderly population over the decades. However, concerns regarding the aging population and its impact on country's socio-economic status have come to the forefront in the policy making and implementation towards national development in recent years. This paper is intended to discuss ethical issues, in context of principlism, that are likely to arise and the means to deal with ethical dilemmas in healthcare of elderly people involving seniors themselves and their service providers whether professionals or family members. To provide the highest level of care, the entire caregiving team needs to form a partnership having the best interest of the elderly people as their focal point while providing loving, appropriate care to enhance their quality of care, their quality of life and their happiness in the latter days of their lives which is coined as 'healthy ageing'.
\end{abstract}

Key words: Elderly people; ageing population; elderly care ethics; healthy ageing; public health

Introduction: Bangladesh is a low-income country of South Asia region. For a realistic statistical definition for ageing in this region, particularly taking into account the average retirement age, legislation, national demographic categories, health conditions and so on, the elderly population in the context of South Asian countries has been defined as those who have reached 60 years of age. ${ }^{1}$ The elderly population (aged 60 years and above) in Bangladesh in 1911,1951, 1981 and 1991 were 1.37, 1.86, 4.90 and 6.05 million respectively and the projected figures for 2000, 2015 and 2025 are 7.25, 12.05 and 17.62 million. The number of elderly persons in Bangladesh was projected to double from 7.8 million in 2001 to 16.2 million by $2025 .^{2}$ Population ageing and the associated growth in the size of elderly populations have a number of troubling policy implications. Countries like Bangladesh are struggling with the healthcare infrastructure and health budget. Still concerns regarding the aging population and its impact on country's socio-economic status have come to the forefront in the policy making and implementation towards national development in recent years. ${ }^{3}$ The World Health Organization (WHO) has also recognized the critical role of both public and private health care service 
of older people worldwide and the need for these centers to be accessible and adapted to the needs of older population. ${ }^{4}$ However, ethical concerns in health care services are universal, and therefore, ethics in health care for elderly population should be addressed in all type of resource-settings throughout the country.

Ethics and morality are not always equivalents. Ethics is frequently known the study of morals and, as such, is the study of what ought to happen, for the elderly and their healthcare providers; however, ethics can mean different things. For the elderly, ethics is about how they want to be treated and allowed to make their own decisions. For family members as caregivers, ethics is about doing what is right even when no one is looking. For professionals providing eldercare, ethics is about adherence to established canons of ethics promulgated by different professional organizations, e.g. In the United States, the American Medical Association for physicians, the American Nurses Association and National Association of Social Workers have their own code of ethics. However, in a country like Bangladesh where bioethics is still demanding to flourish and get an institutional shape, ethics of elderly care is very crucial to any discussion or reflection on ageing and health care. ${ }^{5}$ This paper is intended to discuss ethical issues that are likely to arise and the means to deal with ethical dilemmas, in context of 'Principlism', ${ }^{6}$ in healthcare of elderly people involving seniors themselves and their service providers whether professionals or family members and the needs of professional ethical framework in elderly care.

\section{Some important ethical dilemmas in elderly health care settings}

1. Conflicts of interest: There are several scenarios under which conflicts of interest may arise when family members and professional caregivers assist or represent the elderly people. Those include:

a) conflicts involving spouse and his/her wishes versus the elder's wishes and interests;

b) conflicts involving family members from different generations and their wishes versus the elder's interest;

c) conflicts involving a fiduciary (such as a guardian, conservator or agent under a power of attorney) who may have interests different than the elder; and

d) conflicts involving the care provider's business interests versus the elder's interests, well-being and quality of life.

2. Confidentiality: In the course of eldercare, family members and caregivers frequently gather a substantial amount of confidential information about the client. They owe a duty of confidentiality to the elder. Not only must they not breech the confidence placed in them by releasing that private information to others, but also they must not use that information for their own benefit in such a way as to be adverse to the elder, the source of the private information.

3. Decision-making capability: The elder may have capacity (be competent) or may not be competent to properly participate in the process of making decisions, both business and medical. Such decisions 
will likely have lasting effects on the elder's future, even to his/her end of life. Hence, eldercare providers have a duty to focus on the elder's needs, both present and future. At all times, his/her interests must be considered and weighed heavily in all decision-making, especially when the elder is unable to think clearly about the decisions and the consequences thereof or to express himself/herself clearly about them.

4. Veracity, the rule of truth telling: It can sometimes be overridden by other important factors, such as a responsibility to avoid 'unnecessary distresses. It is also true that some elders do not always wish to be told the full truth. There is no universal agreement as to what extent it is permissible to either lie or to withhold full information from a patient.

5. Fidelity or accountability: It is the willingness of the eldercare provider or family member to be loyal to the elder and assume responsibility for the nature and quality of the care the elder needs and receives within limits of the law. Caregivers' primary responsibility is to promote the well-being of clients. However, medical service providers/social workers' responsibility to the larger society or specific legal obligations may sometimes supersede the loyalty owed clients, and clients should be so advised. Health care institutions, state boards regulating professionals, agencies regulating care providers and society as a whole can also hold others accountable.

Principlism: the dominant ethical framework: The dominant theory or model for modern medical ethics or bioethics is 'Principlism'. ${ }^{6}$ Although arose in the context of medicine, 'principlism' seems to be an appropriate framework for guidance in confronting ethical issues and making ethical decisions in situations elder caregivers of all kinds encounter. ${ }^{6}$ That is why we have considered it in this paper. "Medicine, even at its most technical and scientific levels, is an encounter between human beings, and the physician's work of diagnosing disease, offering advice, and providing treatment is embedded in a moral context." 7 This statement well describes the encounters other professionals involved in eldercare have each day and the proper context for their efforts to provide appropriate care.

Expanding Principlism beyond its medical context, this framework suggests that caregiving ethics begins, initially, with a determination of the condition, an understanding of the situation or a recognition of the problem or conflict, coupled with respect for patient autonomy, followed by the application of the essential principles of beneficence, nonmaleficence, and justice (loyalty and fairness) along with respect for the sanctity of the life of the one being cared for. Thus Principlism may be understood as a framework within which particular cases (issues or conflicts or moral problems) are analyzed and addressed to an appropriate conclusion. Principlism is not merely a set of "rules" per se "because prima facie principles do not contain sufficient content to address the nuances of many moral circumstances."

When understood and applied by all members of the team of service providers and caregivers, this Principlism framework can be helpful in ethical decision-making to benefit the elder and enhance their 
quality of life. However, this is particularly true where the elder's capacity to make decisions or to consent to treatment is questionable. Each of the four essential principles in the proposed framework is discussed below:

1) Autonomy - respect for the elders' choices: Respect for individuality is a core value in our society and is no less so when dealing with the elderly. In fact, it may be even more needed because the elderly are usually not as able as the younger population to stand up for their rights and their decisions. Implicit within any discussion of autonomy is the concept of equality, at least as it relates to human dignity. Autonomy is the natural by-product of that value and is therefore an ideal foundation on which to build the Principlism ethical framework.

Eldercare providers owe the elder the duty to respect his autonomy. In the process, health care providers may have to stand in the gap by being an advocate to preserve the elder's essential autonomy. Two conditions are essential for autonomy - freedom i.e. independence from controlling influences; and capacity for independent decision-making and intentional action. Autonomy is, therefore, essentially involved in the elder being able to give his 'informed consent' to medical treatments as well as to agree to courses of action proposed by caregivers. Exercising autonomy depends upon relevant information and implies a capacity to use that information, which is coined as 'informed consent' ${ }^{6}$ The principlism approach to dealing with ethical conflicts, in medicine, begins by educating the clients or patients concerning available options and the probable consequences of each option. Unless autonomy is counterbalanced against another principle, the client exercises autonomy by choosing among his options. For an example, a senior citizen diagnosed with cancer, having all his mental faculties and has been fully informed of the benefits and consequences of various treatments, may refuse invasive treatment and elect to have alternative therapies of acupuncture and natural remedies. In this, he is utilizing his rights of autonomy. Likewise, an octogenarian with capacity to decide and with necessary information about his options may choose the location for his skilled nursing care despite the recommendation of a health care service provider.

Autonomy can be expressed, and to some extent be exercised, by the elder through the use of 'advance directives' created and signed by the elder under the existing laws in some of the western countries. ${ }^{6}$ By doing so, the elder can express his intentions and have an assurance that decisions made in his autonomy while having capacity will be maintained and respected when he does not have capacity or when he cannot express his decisions.

2) Beneficence - do good: Beneficence is defined as the doing of good; active goodness or kindness; charity. Eldercare providers of all kinds can do well by doing good. Those who embrace and incorporate the principle of beneficence in their ethical decision-making can make a great difference in 
the quality of life that elders enjoy. When the elder needs assistance, the family members are usually the first to step in - unless the emergency medical situation arises where emergency medical technicians are the first on the scene. In a life-threatening emergency, in which the patient may be unconscious, surgery may be performed before the patient's consent can be obtained. Thus the principle of beneficence is put into practice by saving the elder's life. This occurs after a determination has been made that without intervention and consent the patient would expire. Here beneficence trumps autonomy because it cannot be expressed by the elder. If the situation is not an emergency requiring immediate hospitalization or similar intervention, the elder's family member, acting as a surrogate, will quite likely seek the assistance of the appropriate healthcare team, be it the hospital, physician, nursing staff or other eldercare providers such a home healthcare or a skilled nursing facility. The problem inherent with beneficence - no matter what member of the eldercare team is trying hard to do good - is that beneficence may easily change into paternalism. ${ }^{6}$ By their superior training, knowledge, and experience, professionals such as physicians, nurses and caregivers may cross the line from beneficence to paternalism. They are better positioned to determine and advocate for the elder's best interest than is the elder him/herself. However, those superior qualifications are neither a mandate nor permission to overrule the elder's wishes without respecting the elder's autonomy. However, sometimes by trying too hard to do good, a care provider may actually do emotional or psychological, if not physical, harm. For example, an old patient is told by his physician that he must have surgery immediately without giving the patient full information about the reason for this surgery, the risks and benefits, and any complications that might result. Also, the patient has not been given any options or an opportunity for a second opinion or discussion with others. While the physician may be correct, his beneficence that overrides the autonomy of the competent patient results in paternalism.

3) Nonmaleficence - do no harm: Eldercare providers who adhere to the ethical framework of Principlism incorporate the principle of nonmaleficence by doing no harm. The principles of nonmaleficence and beneficence are particularly significant for the elderly and their future quality of life. However, calculating a cost-benefit analysis of medical treatment for older patients is much more difficult than calculating such an analysis for younger patients. Cost-benefit considerations in the elderly are generally more subtle and more complex, as sometimes harm is more likely and benefit is less certain. ${ }^{6,8}$ For example, a man who was given a knee replacement operation and was allowed to die at his wife's request; it was not because the knee operation was unsuccessful, rather he developed a pulmonary complication that would have compromised his quality of life to an intolerable degree.

Sometimes considerations also enter into deliberations about whether or not to hospitalize an elderly patient, e.g. family members of elders want to save money by not spending on nursing home care rather convince to take care by themselves. Some service care providers here (as well as the families they are trying to benefit) violate the principle of nonmaleficence. 
4) Justice: The fourth principle is justice which is a broader societal issue concerning the allocation of limited health care resources ${ }^{6}$. It is not something physicians deal with in day-to-day interactions with patients, nevertheless very important - that is how do you approach giving health care with limited budgets in a resource poor setting in a low-income country. There are two opposing sides, the strictly utilitarian ethical viewpoint and then there's the idealistic..$^{8,9}$

The supporters of the utilitarian viewpoint say that limited health care resources should be allocated to do the most good for the largest number of people. Supporters of an offshoot of this utilitarian viewpoint would allocate resources where they are most likely to be successful, where the good results will be the most prolonged and where they will help the most people. However, such approach may really impact negatively on older people in terms of health care delivery. This is because the success of interventions is less in the elderly, the length of time the intervention will last is going to be less and, in most areas, the elderly do not constitute the bulk of the population. ${ }^{6,7,9}$ Moreover, we would like to point out that rationing can be detrimental to the aged because it affects women more than men. Above age 60, approximately for every 70 men there are 100 women. ${ }^{2}$ Any strictly utilitarian approach to allocating resources based on age is going to willy-nilly have an effect that will be disproportionally felt by women. ${ }^{9}$

On the basis of the idealistic approach to justice, we should give help to people who need it the most. However, with this approach, the elderly will disproportionally need more health care budget/money than younger people, Critically thinking, between these two options, perhaps there is a way to not totally disenfranchise older people and not totally do something using all our health care resources without thinking of the usefulness in terms of prolonged effect for the greatest number of people., ${ }^{9,10}$ Moreover, the principle of justice invokes yet another, related duty - to respect the elder's human dignity. ${ }^{6,9,10}$ Respect for human dignity is also the source of the essential autonomy principle. ${ }^{6,7} \mathrm{We}$ tried here to discuss the ethical concerns and issues in elderly care where one party is elder population and the other one is health care service providers or caregivers; that is how relational ethics perspective refers to the reflection on the challenges encountered in person's relationship with others and on how to fulfil social roles and obligations in a good way.

Conclusion: Ethical professional conduct while delivering eldercare will enhance the stature and credibility of the health professionals and caregivers within their community and encourage others to act in manner alike. Most importantly, in the end, the elders will be benefitted the most for their quality of life will be improved as we work in their best interest. Concerns regarding the ageing population and its well-being are coming to the forefront in Bangladesh in recent years, though they have been less documented and explored than that of the other parts of the world where population 
ageing has advanced further. Last but not the least, to provide the highest level of care, the entire caregiving team needs to form a partnership having the best interest of the elderly people as their focal point while providing loving, appropriate care to enhance their quality of care, their quality of life and their happiness in the latter days of their lives which is coined as 'healthy ageing.

\section{References}

1. Flora MS. Ageing: a growing challenge. Bangladesh Medical Journal 2011; 40(3): 48-51.

2. Bangladesh Bureau of Statistics. Population Census 2001: Preliminary Report. Dhaka: Bangladesh Bureau of Statistics, Ministry of Planning, Government of the People's Republic of Bangladesh; 2009.

3. Tanira S, Nurunnabi ASM, Sony SA, Khatun R. Elderly population of Bangladesh: a public health concern. Journal of Health Science, Research \& Policy 2015; 2(1): 2-7.

4. World Health Organization. Active ageing series: Towards age-friendly primary health care. France: World Health Organization. 2004.

5. Ludwick R, Silva M. Ethics column: Ethical challenges in the care of elderly persons. Online Journal of Issues in Nursing 2003; 9(1). Available: www.nursingworld.org/MainMenuCategories/ANAMarketplace/ANAPeriodicals/OJIN/TableofContents Volume92004/No1Jan04/EthicalChallenges.aspx (seen on May 2016)

6. Beauchamp TL, Childress JF. Principles of biomedical ethics. $7^{\text {th }}$ ed. Oxford: Oxford University Press; 2012.

7. Jonsen AR, Siegler M, Winslade WJ. Clinical ethics: a practical approach to ethical decisions in clinical medicine. $7^{\text {th }}$ ed. New York: McGraw-Hill; 2010.

8. Meyers C. A practical guide to clinical ethics consulting: expertise, ethos and power. Maryland: Rowman \& Littlefield: 2007.

9. Brock DW. Justice, health care, and the elderly. Philosophy \& Public Affairs 1989; 18(3): 297312.

10. Callahan D. Setting limits: medical goals in an aging society with "a response to my critics". $1^{\text {st }}$ reprint ed. Washington, DC: Georgetown University Press; 1995.

Conflict of Interest: Declared non 